\title{
O Supremo Tribunal Federal e a garantia do direito à educação
}

\author{
ELISÂNGELA ALVES DA SILVA SCAFF \\ Universidade Federal da Grande Dourados, Dourados, MS, Brasil
}

ISABELA RAHAL DE REZENDE PINTO

Universidade de São Paulo, São Paulo, SP, Brasil

RESUMO

Neste artigo investiga-se e analisa-se a atuação do Poder Judiciário, especificamente do Supremo Tribunal Federal (STF), com relação às demandas judiciais no campo do direito à educação de crianças e adolescentes no período de 2003 a 2012. Por meio da referida análise observou-se que o STF tem adotado posicionamento favorável em prol da efetivação do direito à educação, declarando de forma unânime que a educação - incluindo a educação infantil - é direito fundamental social, imediatamente exigível do Estado (em sentido amplo) por meio de via judicial. Não obstante a importância da posição jurisprudencial assumida pelo STF, observou-se também na análise desenvolvida a falta de diálogo da Corte com a área educacional bem como o tratamento pouco aprofundado dado ao tema.

\section{PALAVRAS-CHAVE}

direito à educação; judicialização da educação; Supremo Tribunal Federal. 


\section{THE SUPREMO TRIBUNAL FEDERAL AND THE GUARANTEE OF THE RIGHT TO EDUCATION}

\section{ABSTRACT}

This paper investigates and analyzes the role of the judicial power, specifically the Supremo Tribunal Federal (STF), concerning the judicial demands in the field of the right to education of children and adolescents in the period of 2003-2012. Through this analysis it was observed that the STF has adopted a favorable position towards the realization of the right to education, stipulating that education - including childrens education - is a fundamental social right directly liable to judicial process by the State. Notwithstanding the importance of this jurisprudential position taken by the STF, it was observed in the analysis that there is a lack of dialogue with the educational field as well as the in-depth treatment given to the subject.

\section{KEYWORDS}

right to education; judicialization of education; Supremo Tribunal Federal.

\section{EL SUPREMO TRIBUNAL FEDERAL Y LA GARANTÍA DEL DERECHO A LA EDUCACIÓN}

RESUMEN

En este artículo se investiga y analiza el rol de la judicatura, en concreto del Supremo Tribunal Federal (STF) de Brasil, relativo a las demandas judiciales en el ámbito del derecho a la educación de niños y adolescentes en el período del 2003 al 2012. Mediante este análisis se observó que el STF ha adoptado una posición favorable a la efectuación del derecho a la educación, declarando de forma unánime que la educación -incluida la educación infantil- es un derecho social fundamental inmediatamente exigible del Estado (en sentido amplio) por vía judicial. No obstante la importancia de la posición jurisprudencial adoptada por el STF de Brasil, se observó también en el análisis desarrollado la falta de diálogo del STF con el área de la educación, así como el tratamiento de poca profundidad dado al tema.

derecho a la educación; judicialización de la educación; Supremo Tribunal Federal. 


\section{INTRODUÇÃO}

A atuação do Poder Judiciário brasileiro no campo das políticas públicas, especialmente no âmbito dos tribunais superiores, nunca foi tão debatida nos diferentes espaços sociais como nos últimos anos. Importantes decisões relacionadas a temáticas que envolvem questões usualmente analisadas e determinadas no âmbito dos poderes Executivo e Legislativo demonstram um novo papel assumido pelo Poder Judiciário. Exemplos dessa “judicialização da política" ${ }^{1}$ são as recentes decisões do Supremo Tribunal Federal (STF) que envolveram o reconhecimento da união estável para casais do mesmo sexo (ADI 4.277 e ADPF 132) (Brasil, 2011b, 2011c) a constitucionalidade das cotas raciais (RE 597.285) (idem, 2012a) e o reconhecimento da possibilidade da interrupção da gestação de feto anencefálico (ADPF 54). A educação, por sua vez, não está imune a esse processo.

Especialmente a partir da promulgação da Constituição Federal de 1988, o Poder Judiciário passou a exercer um papel mais ativo e diferenciado com relação à educação, passando a julgar litígios e requerimentos que buscavam a regulação, concretização e efetividade desse direito. De acordo com Cury e Ferreira (2009, p. 33), "pode-se designar este fenômeno como a 'judicialização da educação', que significa a intervenção do Poder Judiciário nas questões educacionais em vista da proteção desse direito". Não obstante essa realidade, as pesquisas desenvolvidas no país sobre as decisões judiciais em matéria educacional ainda são incipientes e, em sua maioria, bem recentes (Silveira, 2010). ${ }^{2}$

Deve-se destacar que, embora novidade no Brasil, a análise da jurisprudência educacional nos Estados Unidos já é um tradicional objeto de pesquisa, tendo-se inicialmente fundamentado na análise de uma decisão da Suprema Corte de 1954, mais precisamente do caso de Brown contra o Conselho de Educação (Brown versus Board of Education of Topeka), em que ficou estabelecido pela Suprema Corte Federal que, no campo da educação pública, a política da segregação racial é inconstitucional. Valendo-se dessa decisão, a história da jurisprudência educacional norte-americana evoluiu para a discussão da igualdade em relação ao financiamento educacional e, mais recentemente, para a discussão acerca da "adequação" ou "eficiência" da aplicação dos fundos educacionais no país (Rebell, 2002).

No Brasil, observa-que a Carta Constitucional de 1988 garantiu especial atenção e destaque ao direito à educação, consagrando-o como o primeiro dos direitos fundamentais sociais em seu artigo $6^{\circ}$ e detalhando-o especialmente do artigo 205 em diante. Logo nesse artigo, a Carta Constitucional estabelece a educação como direito de todos e dever do Estado e da família, destacando como seus objetivos o pleno desenvolvimento da personalidade humana e o preparo para o exercício da cidadania e a qualificação para o trabalho (Brasil, 1988).

1 Apesar da falta de consenso quanto ao alcance e significado do termo, entende-se que a judicialização da política relaciona-se com a maior presença do Poder Judiciário em questões políticas tradicionalmente analisadas pelos poderes Legislativo e Executivo (Verbicaro, 2008).

2 Para conferir os trabalhos produzidos no Brasil relacionados à judicialização da educação, ver Pinto (2014, p. 14-16). 
Além dessa previsão, a Constituição Federal de 1988 estabelece cerca de trinta disposições referentes ao direito à educação visando a sua efetivação, destacando-se entre elas: a garantia do ensino obrigatório e gratuito como direito público subjetivo (artigo $208, \S 1^{\circ}$ ), assegurando também sua oferta gratuita àqueles que a ele não tiveram acesso na idade própria (artigo 208, inciso I); a responsabilização das autoridades competentes pelo não oferecimento do ensino obrigatório e gratuito ou por sua oferta irregular (artigo 208, § 2०); a indicação dos princípios e objetivos sob os quais o direito à educação deve ser concretizado (artigo 206); o estabelecimento de competências legislativas em matéria educacional (artigo 22, inciso XXIV e artigo 24, inciso IX); a repartição de competências administrativas na efetivação do direito à educação (artigo 211); a organização do financiamento educacional (artigo 212 e artigo 213) e o estabelecimento das garantias e meios judiciais para a sua concretização (Brasil, 1988).

Não obstante a expressa previsão e regulamentação do direito à educação nos diversos dispositivos constitucionais e infraconstitucionais, há ainda muita polêmica quando se trata da sua exigibilidade pela via judicial, especialmente no que diz respeito à:

a) compreensão de sua natureza jurídica: seriam normas impositivas (obrigações) ou meros “conselhos", "objetivos" constitucionais?;

b) titularidade: seriam direitos individuais ou podem envolver a dimensão coletiva e social?;

c) alcance de seu objeto: o direito à educação é o direito ao acesso a vagas na escola ou o direito à realização de políticas públicas? (Duarte, 2007).

Além desse panorama específico que envolve o direito à educação, cabe salientar que os direitos sociais em geral encontram diversos obstáculos para sua concretização pela via judicial. Entre outras objeções, citem-se: a discussão acerca do desrespeito ao princípio da separação dos poderes; a alegada desconsideração ao regime democrático; a escassez de recursos públicos formulada sob a designação de "reserva do possível"; o impacto negativo das decisões judiciais concessivas de direitos sociais na organização e planejamento das políticas públicas e da própria administração; a incapacidade técnica do Judiciário para analisar e formular políticas públicas, objeto por excelência dos direitos sociais; a crítica acerca da desigualdade quanto ao acesso à justiça, além da sempre aposta crítica com relação à eficácia dos direitos sociais, econômicos e sociais, ou seja, com relação ao argumento de que esses direitos seriam meros "programas" a serem executados pela administração pública discricionariamente (Neto, 2010).

Embora esses pontos de vista venham sendo aos poucos superados, ainda não é consensual a discussão acerca da possibilidade e dos limites de o Judiciário condenar o Poder Público a prover prestações materiais aos indivíduos ou à coletividade, especialmente quando envolve a implementação de políticas públicas e sua dimensão coletiva. Importante lembrar que paralelamente ao movimento de afirmação dos direitos sociais e construção do Estado de bem-estar social na Constituição Federal de 1988, foram implementadas no país políticas que visavam à contenção do dispêndio 
de recursos públicos e implicavam uma maior abstenção do Estado na concretização dos direitos sociais (Oliveira; Araujo, 2005). Observa-se, assim, que a atuação do Poder Judiciário na concretização dos direitos sociais não diz respeito apenas a uma questão de interpretação do direito, mas também de decisão política (Neto, 2010).

Diante dessas indagações e questionamentos existentes a respeito da concretização do direito fundamental social à educação por meio da via judicial, propõe-se neste artigo investigar e analisar a atuação do Poder Judiciário, especificamente do $\mathrm{STF}$, com relação às demandas judiciais no campo do direito à educação de crianças e adolescentes.

O recorte institucional da pesquisa, tendo o STF como o órgão judicial escolhido para ter suas decisões analisadas, justifica-se:

a) pela pertinência temática da corte, tendo em vista que, diante da ampla garantia e detalhamento do direito à educação no texto Constitucional, o STF, atuando como o Tribunal Constitucional do país, surge como um espaço privilegiado para análise de questões educacionais;

b) pelas atribuições constitucionais do STF, que envolvem o controle de constitucionalidade de leis e atos normativos federais, estaduais e distritais e a função de via recursal de última instância, decidindo de forma definitiva sobre questões inicialmente questionadas em outros órgãos do Poder Judiciário;

c) pela relevância decisória do STF, que atua como órgão de cúpula do Poder Judiciário influenciando a atuação das demais instâncias jurisdicionais e vinculando a atuação dos membros do Poder Judiciário e da administração pública por intermédio das súmulas vinculantes e das ações direta de inconstitucionalidade e declaratória de constitucionalidade;

d) por seu papel de destaque no processo de judicialização da política, assumindo nos últimos anos posição central no sistema político brasileiro ao atuar de forma crescente no campo das políticas públicas (Vieira, 2008).

Como recorte temporal da análise, definiu-se o período de 1/1/2003 a 31/12/2012, correspondendo ao atual e ainda em desenvolvimento momento histórico do STF, marcado pela atuação mais ativa e política da corte e de seus membros e pela maior presença do Poder Judiciário em áreas que tradicionalmente não ocupava e em temáticas sobre as quais até então não deliberava (Ferreira; Fernandes, 2013). Como efeito, o STF surge na última década como um dos principais atores do processo de judicialização da política e, especificamente no caso dos direitos educacionais, da judicialização da educação. Como destaca Ribeiro (2012, p. 88), "pesquisas empíricas sobre essa Corte [...] revelaram que o STF, longe de ser um órgão judicial neutro, age como verdadeiro policy maker [...]".

$\mathrm{Na}$ pesquisa apresentada, foram analisados apenas os acórdãos, ${ }^{3}$ por representarem a decisão final tomada coletivamente pelo STF. Nesse sentido, restam ex-

3 O acórdão é o texto da decisão proferida por um tribunal. Nesse sentido, diferencia-se da sentença, da decisão interlocutória e do despacho, que são decisões monocráticas, proferidas por apenas uma pessoa (Nery Junior, 2006). 
cluídas as decisões monocráticas, espécie de decisão tomada por apenas um ministro e que analisa pedidos ou recursos inadmissíveis ou improcedentes, ou seja, aqueles que forem propostos sem o cumprimento dos pressupostos previstos em leis bem como aqueles em que a ação apresentar tese jurídica contrária ao posicionamento dominante do STF sobre a temática (Brasil,1973). Deve-se destacar que, embora as decisões monocráticas representem a grande maioria das decisões emitidas pelo STF, estas, em regra, discorrem sobre questões processuais e, quando tratam do mérito (conteúdo) da ação, devem necessariamente seguir aquilo que já foi estabelecido em acórdãos da própria corte. Também foram excluídas questões em que o conteúdo das decisões não foi analisado, tendo em vista que para o objetivo da pesquisa não é relevante o estudo de questões meramente processuais, embora se deva destacar que a decisão de não analisar determinada ação ou recurso por questões processuais compreende não apenas uma decisão jurídica, mas também política.

\section{O DIREITO FUNDAMENTAL SOCIAL À EDUCAÇÃO}

A Constituição Federal de 1988, promulgada no processo de redemocratização do país, garantiu especial atenção aos direitos fundamentais sociais, entre os quais o direito à educação. Diz o artigo 60: "São direitos sociais a educação, a saúde, a alimentação, o trabalho, a moradia, o lazer, a segurança, a previdência social, a proteção à maternidade e à infância, a assistência aos desamparados, na forma desta Constituição" (Brasil, 1988, grifos nossos).

A afirmação dos direitos sociais na atual Carta Constitucional brasileira está inserida no contexto da afirmação político-jurídica do Estado social e democrático de direito no país. É a própria Constituição que estabelece, explicitamente em seu artigo $1^{\circ}$, que o Brasil constitui-se como um Estado democrático de direito, fundamentado na cidadania, na dignidade da pessoa humana e no pluralismo político. Ademais, embora o referido artigo não o diga expressamente, fica claro o caráter social desse Estado democrático de direito ao se analisar mais detidamente a Carta Constitucional brasileira.

De fato, no artigo $3^{\circ}$, o texto constitucional estabelece como objetivos fundamentais do país a construção de uma sociedade livre, justa e solidária; a erradicação da pobreza e da marginalização; a redução das desigualdades sociais e regionais e a promoção do bem de todos, sem preconceitos ou discriminação de qualquer tipo. Estabelece ainda, como já referido, diversos direitos sociais e garante amplos direitos trabalhistas nos artigos 7o a 11 da Constituição Federal (Brasil, 1988). A adoção desse modelo de Estado pela Carta Constitucional brasileira passa a impor ao governo federal não apenas o respeito aos direitos individuais (direito de propriedade, direito à liberdade religiosa, direito de ir e vir etc.), mas também a concretização dos direitos sociais por meio da elaboração e implementação de políticas públicas (Duarte, 2007).

A inclusão do direito à educação no elenco dos direitos fundamentais sociais é uma afirmação inconteste no atual sistema jurídico brasileiro. Isso porque a Constituição Federal de 1988 o incluiu expressamente em seu capítulo II, denominado "Dos direitos sociais" que, por sua vez, está contido no título II, nomeado de 
"Dos Direitos e Garantias Fundamentais" bem como o declarou como direito de todos e dever do Estado em seu artigo 205, detalhando seu conteúdo em seus artigos subsequentes. Além dessa previsão de caráter formal, o direito à educação "é direito fundamental porque [...] consubstancia-se em prerrogativa própria à qualidade humana, em razão da exigência da dignidade" (Caggiano, 2009, p. 22).

Embora não exista unanimidade conceitual quanto ao sentido da expressão "direitos fundamentais", pode-se compreendê-la como direitos do homem consagrados pelo Estado nacional em suas cartas constitucionais e que tem como nota distintiva sua fundamentalidade, ou seja, sua indispensabilidade para o ser humano e para a garantia de sua dignidade e desenvolvimento como pessoa (Silva, 2007).

A primeira consequência dessa caracterização da educação como direito fundamental é o tratamento jurídico diferenciado que a ela deverá ser dispensado, a saber: a sua aplicabilidade imediata (artigo $5^{\circ}, \S 1^{\circ}$ ) e a impossibilidade da sua supressão da ordem constitucional (artigo 60, $§ 4^{\circ}$, inciso IV). Ademais, a inserção do direito à educação entre os direito fundamentais impõe ao Estado um comportamento ativo "seja i) criando condições normativas adequadas ao exercício desse direito (legislação), seja ii) na criação de condições reais, com estruturas, instituições e recursos humanos" (Tavares, 2010, p. 781).

De fato, a compreensão do direito à educação como um direito fundamental tem como uma de suas principais consequências a possibilidade de o cidadão exigir do Estado a sua concretização. E a inovação trazida pela Constituição Federal de 1988 é a de possibilitar ao indivíduo ou coletividade exercer esse direito mediante via jurisdicional, ou seja, por meio do Poder Judiciário.

Silva (2007), corroborando esse entendimento, sustenta que a declaração da educação como direito fundamental social no artigo $6^{\circ}$ da Constituição Federal, aliada à declaração da educação como direito de todos e dever do Estado no artigo 205 do mesmo documento, criou uma situação jurídica subjetiva, em que o Estado tem a obrigação inescusável de prestar o serviço público essencial da educação a todos os cidadãos, podendo até mesmo ser demandado judicialmente para efetivar seu dever.

Trata-se, nesse sentido, de considerar a educação como um verdadeiro direito público subjetivo. Esse conceito, de grande relevância no campo judicial, refere-se a um termo técnico jurídico construído no contexto do Estado liberal burguês e da afirmação dos direitos individuais e que permitiu ao indivíduo pleitear judicialmente perante o Estado direitos consagrados nos documentos legais ou, em outras palavras, permitiu "transformar a norma geral e abstrata contida num determinado ordenamento jurídico em algo que possua como próprio. A maneira de fazê-lo é acionando as normas jurídicas (direito objetivo) e transformando-as em seu direito (direito subjetivo)" (Duarte, 2004, p. 113).

A construção desse conceito foi fruto de um processo de limitação do poder estatal, estando fortemente relacionada com a garantia dos direitos civis e políticos do homem, o que ensejava por parte do Estado um dever de não fazer, de não desrespeito aos direitos individuais e de não intervenção na esfera de liberdade do homem. Com a afirmação do Estado social, no entanto, a configuração tradicional do conceito de direito público subjetivo se transformou, passando a englobar também a possibilidade de se exigir do Estado um comportamento ativo, interventor, de concretização dos direitos sociais e de realização de políticas públicas (Duarte, 2004) 
Observa-se, ademais, que a educação, para além de um direito fundamental e de direito público subjetivo, caracteriza-se como um direito de natureza social. Duarte (2007, p. 697), destacando o referido caráter social do direito fundamental à educação, salienta que esse direito tem "uma dimensão que ultrapassa, e muito, a consideração de interesses meramente individuais". Trata-se, de fato, de um direito que carrega irrecusavelmente uma faceta coletiva, especialmente "porque na educação está em jogo o Bem Comum" (Monteiro, 2003, p. 768). No mesmo sentido, Duarte (2004) destaca que a concretização a contento dos direitos educacionais acarreta benefícios não apenas aos estudantes e alunos, uma vez que, indiretamente, facilita e fomenta o desenvolvimento social e cultural de toda a coletividade.

A afirmação do direito à educação como um direito fundamental de natureza social tem uma consequência importantíssima, visto que, por intermédio dela, reconhece-se que, embora o direito à educação possa ser efetivado e exigido judicialmente de maneira individual, a sua concretização ocorrerá por meio da realização de políticas públicas. Como afirma Duarte (idem, p. 710), isso significa que "a satisfação do direito não se esgota na realização do seu aspecto meramente individual [...], mas abrange a realização de prestações positivas de natureza diversa por parte do poder público, num processo que se sucede no tempo".

É importante destacar ainda que o direito fundamental social à educação não se refere apenas ao direito fundamental do cidadão a estar matriculado em um estabelecimento de ensino ou mesmo ao direito da coletividade a uma política pública que se restrinja à dimensão do acesso à educação. Como destaca Tavares (2010, p. 781), “o dever estatal quanto ao direito fundamental à educação está longe de se esgotar no mero oferecimento de acesso". Com efeito, a Constituição Federal de 1988 em nenhum momento limitou a abrangência do direito fundamental à educação ao seu acesso, como é comumente entendido por estudiosos da temática e por juízes e tribunais. Sabe-se que o mero acesso à vaga em uma instituição de ensino não é suficiente para garantir em plenitude a dignidade do ser humano, bem como o desenvolvimento da pessoa, seu preparo para o exercício da cidadania e sua qualificação para o trabalho, nos moldes expostos no artigo 205 do texto constitucional. É essencial que se garanta, entre outros aspectos, a igualdade de condições para o acesso e permanência na escola, a valorização dos profissionais da educação escolar e a garantia de padrão de qualidade (artigo 206, incisos I, V e VII), compreendidos como integrantes da própria ideia de fundamentalidade do direito à educação.

\section{DECISÕES JUDICIAIS EDUCACIONAIS DO STF}

As decisões judiciais relacionadas ao direito à educação de crianças e adolescentes no âmbito do STF no período de 2003 a 2012 foram coletadas no sítio eletrônico do órgão, especificamente na seção "Pesquisa de Jurisprudência". ${ }^{4}$

4 Dados disponíveis em: <http://www.stf.jus.br/portal/jurisprudencia/pesquisarJurisprudencia.asp >. Acesso em: 10 jan. 2013. 
Importante destacar que, de acordo com informações da assessoria da corte, são disponibilizados para pesquisa eletrônica todos os acórdãos julgados pelo tribunal no período analisado. Os descritores utilizados na pesquisa jurisprudencial tiveram como base o objeto de estudo da presente pesquisa, optando-se pelos termos mais abrangentes, possibilitando abarcar o maior número de decisões judiciais. Nesse sentido, utilizamos as seguintes palavras: educação, ensino, escola, escolar, criança e adolescente e infância e juventude.

Da pesquisa realizada por meio dos referidos descritores foram selecionadas, após a leitura das ementas (resumos) das ações e recursos encontrados no sítio eletrônico do STF, trinta e cinco decisões pertinentes à temática. $\mathrm{O}$ recorte material da pesquisa documental deteve-se na atuação do Poder Judiciário quanto às decisões judiciais relacionadas ao direito à educação das crianças e dos adolescentes, tendo como recorte legal especialmente a Constituição Federal. Portanto, restaram excluídas as decisões referentes ao ensino superior, aos direitos trabalhistas, a questões tributárias (especificamente relativas ao salário-educação e à imunidade tributária de instituições educacionais), a questões previdenciárias e a questões penais. Após a seleção e leitura integral dos acórdãos, as decisões foram organizadas em um quadro pelo critério da pertinência temática. A análise dos acórdãos foi realizada minuciosamente, ou seja, caso por caso, sendo posteriormente agrupada para melhor exposição no texto, tendo como destaque a argumentação desenvolvida pelos ministros e o resultado das ações e recursos selecionados. A análise foi conduzida fundamentando-se na ordem normativa e na produção bibliográfica jurídica e educacional existentes sobre as temáticas expostas nas decisões judiciais.

Em razão do grande número de atribuições do STF, que incluem a atuação como tribunal constitucional brasileiro e como corte de última instância, os acórdãos julgados por ele sobre a temática do direito educacional de crianças e adolescentes envolveram diferentes questões e temáticas, muitas delas distintas entre si, e foram classificados e organizados por pertinência temática em doze categorias apresentadas no Quadro 1.

Do conjunto de acórdãos analisados, observou-se que a temática mais presente no STF em relação ao direito à educação refere-se às demandas por acesso a vagas na educação infantil, representativas de $20 \%$ das ações analisadas. Em seguida, estão os acórdãos referentes ao conflito entre os poderes Legislativo e Executivo na elaboração de normas para a educação, com 6 ações analisadas (cerca de 17\%); às ações relativas à contratação temporária de profissionais da educação pública, com 5 acórdãos (cerca de 14\%); os acórdãos referentes ao conflito entre União e os estados membros na elaboração legislativa na temática educacional, com 4 acórdãos (cerca de 11,5\%); as ações alusivas à responsabilidade estatal na garantia ampla do direito à educação e as relativas ao financiamento educacional, ambas com 3 acórdãos cada (cerca de 8,5\%) e os acórdãos relativos ao poder de regulação do Estado em relação aos estabelecimentos privados de ensino, com 2 decisões (cerca de 5,5\%). As demais temáticas estão representadas por apenas 1 acórdão, sendo elas: manutenção de turma do ensino fundamental na modalidade educação de jovens e adultos (EJA); escolha de dirigentes de estabelecimentos de ensino mediante eleições diretas; constitucionalidade da meia-entrada; omissão do presidente da 
República em relação à erradicação do analfabetismo no país e à implementação do ensino fundamental para todos e a constitucionalidade do piso salarial profissional para os profissionais do magistério público da educação básica.

\section{Quadro 1 - Resumo das decisões judiciais proferidas pelo STF sobre o direito à educação de crianças e adolescentes (2003-2012)}

\begin{tabular}{|c|c|}
\hline Categorias & Temas e questões \\
\hline $\begin{array}{l}\text { Acesso à educação } \\
\text { infantil }\end{array}$ & Requerimento de matrícula em creche e/ou pré-escola. \\
\hline $\begin{array}{l}\text { Manutenção de turma } \\
\text { do ensino fundamental } \\
\text { na modalidade EJA }\end{array}$ & $\begin{array}{l}\text { Requerimento para garantir a manutenção de turma do ensino fundamental na } \\
\text { modalidade EJA, extinta pelo governo do estado sob a alegação de baixo número } \\
\text { de alunos matriculados. }\end{array}$ \\
\hline \multirow{3}{*}{$\begin{array}{l}\text { Responsabilidade } \\
\text { estatal na garantia } \\
\text { ampla do direito à } \\
\text { educação }\end{array}$} & Contratação de professores para a rede de ensino público estadual. \\
\hline & Garantia de transporte gratuito de alunos da rede estadual de ensino. \\
\hline & $\begin{array}{l}\text { Requerimento para impelir o Estado a construir salas de aula em número } \\
\text { suficiente ao adequado atendimento da população e com a garantia de padrões } \\
\text { mínimos de qualidade de ensino. }\end{array}$ \\
\hline $\begin{array}{l}\text { Contratação } \\
\text { temporária de } \\
\text { profissionais da } \\
\text { educação pública }\end{array}$ & $\begin{array}{l}\text { Análise da constitucionalidade da contratação de profissionais da educação em } \\
\text { estabelecimentos públicos de ensino por meio de contratos temporários, sem a } \\
\text { realização prévia de concurso público para investidura no cargo. }\end{array}$ \\
\hline $\begin{array}{l}\text { Ação direta de } \\
\text { inconstitucionalidade } \\
\text { por omissão em relação } \\
\text { à erradicação do } \\
\text { analfabetismo no país } \\
\text { e à implementação do } \\
\text { ensino fundamental } \\
\text { obrigatório e gratuito } \\
\text { para todos }\end{array}$ & $\begin{array}{l}\text { Requerimento para ver declarada a omissão do presidente da República e do } \\
\text { ministro da Educação em relação à erradicação do analfabetismo no país e à } \\
\text { garantia de oferta e implementação perene do ensino fundamental obrigatório e } \\
\text { gratuito para todos os brasileiros. }\end{array}$ \\
\hline \multirow[t]{3}{*}{$\begin{array}{l}\text { Financiamento da } \\
\text { educação }\end{array}$} & $\begin{array}{l}\text { Possibilidade de garantir judicialmente o cumprimento da norma constitucional } \\
\text { que impõe a vinculação de determinada porcentagem dos impostos na } \\
\text { manutenção e desenvolvimento do ensino. }\end{array}$ \\
\hline & $\begin{array}{l}\text { Análise da constitucionalidade de lei estadual que vincula parte dos recursos } \\
\text { destinados pelo Estado ao ensino na manutenção e conservação das escolas } \\
\text { públicas por meio de transferência direta de verbas às unidades escolares. }\end{array}$ \\
\hline & $\begin{array}{l}\text { Análise da constitucionalidade da criação e funcionamento do } \\
\text { PARANAEDUCAÇÃO, pessoa jurídica de direito privado instituída com a } \\
\text { finalidade de auxiliar na gestão do sistema estadual de educação, incluindo entre } \\
\text { suas atribuições a de gerir recursos públicos para a educação. }\end{array}$ \\
\hline $\begin{array}{l}\text { Escolha de dirigentes } \\
\text { de estabelecimentos } \\
\text { públicos de ensino } \\
\text { mediante eleições } \\
\text { diretas }\end{array}$ & $\begin{array}{l}\text { Análise da constitucionalidade da realização de eleições diretas para direção } \\
\text { das instituições de ensino mantidas pelo poder público com a participação da } \\
\text { comunidade escolar. }\end{array}$ \\
\hline
\end{tabular}




\begin{tabular}{|c|c|}
\hline Categorias & Temas e questões \\
\hline $\begin{array}{l}\text { Poder de regulação } \\
\text { estatal em relação } \\
\text { aos estabelecimentos } \\
\text { privados de ensino }\end{array}$ & $\begin{array}{l}\text { Análise da possibilidade e dos limites da intervenção estatal na atividade exercida } \\
\text { pela iniciativa privada no âmbito da educação básica. }\end{array}$ \\
\hline Meia-entrada & $\begin{array}{l}\text { Análise da constitucionalidade do direito de pagamento de meia-entrada do valor } \\
\text { cobrado para o ingresso em estabelecimentos das áreas de esporte, cultura e lazer. }\end{array}$ \\
\hline $\begin{array}{l}\text { Inconstitucionalidade } \\
\text { em razão da } \\
\text { inobservância dos } \\
\text { requisitos formais de } \\
\text { produção das normas }\end{array}$ & $\begin{array}{l}\text { Análise da abrangência e dos limites de atuação dos poderes Legislativo e } \\
\text { Executivo na elaboração de normas para a educação. }\end{array}$ \\
\hline $\begin{array}{l}\text { Competências para } \\
\text { legislar }\end{array}$ & $\begin{array}{l}\text { Análise da abrangência e dos limites de competência dos diferentes entes estatais } \\
\text { para legislar sobre temáticas relacionadas à educação. }\end{array}$ \\
\hline $\begin{array}{l}\text { Piso salarial } \\
\text { profissional nacional } \\
\text { para os profissionais do } \\
\text { magistério público da } \\
\text { educação básica }\end{array}$ & $\begin{array}{l}\text { Análise de constitucionalidade de partes da lei n. } 11.738 / 2008 \text {, que instituiu o } \\
\text { piso salarial profissional nacional para os profissionais do magistério público da } \\
\text { educação básica. }\end{array}$ \\
\hline
\end{tabular}

Fonte: Banco de dados da pesquisa.

Elaboração das autoras.

Além de ser a temática mais presente no STF com relação ao direito à educação no período estudado, a análise dos acórdãos referentes às demandas individuais por vaga na educação infantil permite afirmar que o STF tem adotado posicionamento favorável em prol da efetivação do direito à educação. Isso porque, de forma unânime, a corte assentou que a educação - inclusive a educação infantil - é direito fundamental social, imediatamente exigível do Estado (em sentido amplo) mediante via judicial. Em outras palavras, o STF declarou que o direito à educação é direito público subjetivo.

Ademais, dentro dessa mesma temática, a corte enfrentou as principais objeções apostas pelo Estado em relação à exigibilidade judicial dos direitos sociais educacionais, estabelecendo que cabe ao Poder Judiciário - especialmente ao STF em razão de sua dimensão política - atuar na análise, formulação e implementação de políticas públicas nos casos em que os demais órgãos ou poderes estatais competentes não o fizerem, descumprindo expressos mandamentos constitucionais, como é o caso do direito à educação. Estabelece ainda que a mera alegação de escassez de recursos públicos (a denominada "reserva do possível”) por parte da administração pública, sem comprovação fática objetiva, não é suficiente para negar a exigibilidade imediata do direito à educação básica.

Apesar de importante e de ter-se apresentado como relevante indutor de decisões judiciais nos órgãos inferiores no mesmo sentido da decisão emanada (Vicelli, 2012), a decisão judicial do STF, no propósito de reconhecer o direito de acesso à educação, não surpreende, uma vez que, como destaca Silveira (2012), as demandas judiciais com pedidos individuais em prol da garantia do acesso a vagas 
têm sido acatadas de forma quase unânime pelo Poder Judiciário. Mas o STF foi além. Ao analisar os acórdãos referentes à responsabilidade estatal na garantia ampla do direito à educação - os quais tratam especificamente sobre a contratação de professores a fim de suprir a carência da rede de ensino público, a garantia de transporte escolar gratuito e a adequação do número de salas de aula em relação ao número de alunos -, a corte estabeleceu de forma unânime que é dever do Estado propiciar não apenas o direito individual de acesso ao ensino, mas também a garantia dos meios que viabilizem amplamente o exercício do direito social à educação.

Embora cada acórdão analisado nessa categoria trate de um direito específico, protegido por diferentes dispositivos legais e constitucionais, a fundamentação das decisões do STF sobre a temática é ampla: sendo a educação direito fundamental social, é dever do Estado garanti-la em todas as suas dimensões. Ao não adotar argumentação específica em relação a cada direito pleiteado, pode-se inferir duas considerações. A primeira é a de que o STF não limitou o direito à educação a nenhuma legislação ou dispositivo legal existente, apontando para um posicionamento abrangente em relação ao que compreende como responsabilidade estatal na educação, garantindo em amplitude sua efetividade. A segunda questão aponta para o lado oposto: ao não debater em profundidade as questões específicas atinentes a cada direito pleiteado, corre-se o risco de, na prática, não se garantir a exequibilidade da decisão judicial emanada.

E de se destacar, ainda nesse contexto, que, pela primeira vez na história do STF, a corte "flertou" com o tema de qualidade do ensino. Trata-se do agravo regimental no recurso extraordinário n. 635.679, julgado em 6/12/2011 e proposto pelo estado de Goiás objetivando a reforma de decisão do tribunal de justiça daquele estado, que acatou a ação civil pública proposta pelo Ministério Público de Goiás pleiteando a construção de salas de aula em número suficiente ao adequado atendimento da população e em cumprimento ao artigo $4^{\circ}$, inciso IX da Lei de Diretrizes e Bases (LDB), que estabelece que o dever do Estado com a educação será efetivado mediante a garantia de padrões mínimos de qualidade de ensino - definidos como a variedade e quantidade mínimas, por aluno, de insumos indispensáveis ao desenvolvimento do processo de ensino-aprendizagem - e também em cumprimento ao artigo 34 da LDB de Goiás, que estabelece a relação adequada entre o número de alunos e o professor, de modo que esse seja prestado com qualidade e no prazo de seis meses.

Nesse caso, o STF, por unanimidade, acatou a ação civil pública proposta por entender que cabe ao Poder Judiciário determinar que o Poder Executivo adote medidas que assegurem o direito à educação quando este não o faça espontaneamente. O interessante de destacar nessa decisão é que, pela primeira vez, o STF salienta que o dever do Estado com a educação envolve também uma dimensão de qualidade. Na realidade, é a primeira ementa da corte em que a questão da qualidade da educação é citada, ainda que o seu conteúdo não seja debatido pelos ministros.

Com efeito, a questão da exigibilidade judicial do direito à qualidade do ensino é complexa, pois se, de um lado, observa-se que a Constituição Federal (artigo 206, inciso VII) e a LDB (artigo 40, inciso IX) garantem o padrão de qualidade de ensino como um dos princípios norteadores da educação no país, deve-se salientar 
também que a discussão em torno do conceito de qualidade educacional extrapola em múltiplos aspectos a simples análise jurídica. De fato, a qualidade da educação, como objeto social, político e ideológico que é, apresenta-se como conceito polissêmico e em constante evolução, tornando complexa sua análise mediante o Poder Judiciário. Nesse sentido, Oliveira e Araujo (2005, p. 6 e 8) destacam que "é muito difícil, mesmo entre os especialistas, chegar-se a uma noção do que seja qualidade de ensino [...] provavelmente essa questão terá múltiplas respostas, seguindo valores, experiências e posição social dos sujeitos".

Em termos legais, tanto a Constituição Federal quanto a LDB tratam da qualidade de maneira aberta e carente da objetividade necessária para que a questão da qualidade educacional seja colocada perante o Poder Judiciário. Para que demandas judiciais relacionadas com essa dimensão do direito à educação sejam possíveis, seria necessário que se estabelecessem parâmetros de referência para a definição do "padrão de qualidade" exigido nas normas constitucionais e legais. É importante destacar que na decisão anteriormente descrita esses parâmetros de qualidade estavam estabelecidos objetivamente pela LDB de Goiás, razão pela qual o STF não discutiu o conceito de qualidade além do estabelecido legalmente. Aponta-se ainda que a própria construção de indicadores e parâmetros de qualidade que permitem a análise dessa dimensão do direito à educação pelo Poder Judiciário deve ser discutida com cautela, uma vez que:

Além da multiplicidade de formas, os indicadores de qualidade devem ser dinâmicos e constantemente debatidos e reformulados, visto que as diversas expectativas e representações sociais integram um contexto histórico mais amplo e em constante movimento. Assim, a tarefa de definição dos indicadores de qualidade não é somente técnica, mas também política, ou seja, definir insumos e parâmetros para um ensino de qualidade requer uma análise dos custos, das condições reais, dos objetivos que se almeja e das expectativas sociais em torno do processo de escolarização. (Oliveira; Araujo, 2005, p. 18)

Assim, embora não tenha adentrado no campo de discussões acerca do conceito de qualidade na área educacional, restringindo-se à análise da legislação educacional estadual sobre o tema, trata-se de questão cuja análise judicial o STF demonstrou não ter problema em discutir.

Observa-se que a discussão da qualidade do ensino pelo Poder Judiciário já é realidade nos Estados Unidos há mais de duas décadas, por meio das denominadas "adequacy litigations", embora ainda hoje seja uma das questões mais polêmicas no campo do direito à educação norte-americano (Rebell, 2002). Trata-se, na realidade, de múltiplas demandas impetradas em face das cortes estaduais pleiteando o direito a uma educação "adequada" ou "eficiente", com base em dispositivos constitucionais estaduais, muito semelhantes, aliás, aos dispositivos constitucional (artigo 206, inciso VII) e legal (artigo 4o, inciso IV, LDB) previstos no Brasil.

Apesar do posicionamento unânime do STF ao compreender a educação como direito fundamental social, deve-se destacar que todas as ações analisadas pela corte referiam-se a demandas individuais ou ações em que os demandantes pode- 
riam ser individualizados. Ademais, em nenhum momento o STF discutiu o caráter coletivo, propriamente social, do direito fundamental à educação. Compreender a educação como direito fundamental de natureza social no atual Estado social democrático de direito significa compreendê-la como um direito supraindividual, que exige a formulação e prática de políticas públicas e não apenas a garantia individual da criança e do adolescente à instrução escolar. De fato, o STF não parece ter claro o que compreende por políticas públicas, uma vez que, ao afirmar que sua interferência nesse campo é legítima, confunde a garantia de um direito individual mediante via judicial com o próprio processo de formulação e implementação dessas políticas, o qual é muito mais complexo que a expedição de uma decisão judicial de cunho individual. Um exemplo desse posicionamento da corte é a afirmação do ministro Celso de Mello, em decisão referente à requisição de matrícula na educação infantil:

É certo [...] que não se inclui ordinariamente no âmbito das funções institucionais do Poder Judiciário - e nas desta Suprema Corte, em especial - a atribuição de formular e de implementar políticas públicas [...] Impende assinalar, no entanto, que tal incumbência poderá atribuir-se, embora excepcionalmente, ao Poder Judiciário. (Brasil, 2005, p. 9)

Ademais, deve-se destacar que, se em questões envolvendo a responsabilidade do Estado de garantir o direito à educação a crianças e adolescentes, o posicionamento do STF é unânime no sentido de reconhecer a educação como direito público subjetivo, a questão torna-se muito mais complexa e menos consensual quando se trata de analisar questões específicas que, embora integrem o conteúdo do direito fundamental à educação, envolvem também um conjunto de dispositivos legais e constitucionais que não aqueles previstos na legislação educacional ou no capítulo constitucional que trata especificamente desse direito. Nesses casos, como poderá ser observado a seguir pela descrição e análise de algumas temáticas discutidas pelo STF, a posição estabelecida pela corte carece de sistematização, aprofundamento teórico e, especialmente, de um diálogo com a área educacional.

Nessa perspectiva, uma importante questão analisada pelo STF no campo educacional refere-se à possibilidade e aos limites legais para a contratação temporária de profissionais da educação em estabelecimentos públicos de ensino sem a realização prévia de concurso público para investidura no cargo. É importante lembrar que a contratação temporária de professores na rede pública de ensino configura-se como um dos elementos do processo de precarização do trabalho docente (Oliveira, 2004). De fato, ao analisar os dados do Censo Escolar 2012, observa-se que a efetuação de concurso público para contratação de professores já se configura como exceção em pelo menos sete estados do país, ${ }^{5}$ em clara inversão dos preceitos e valores constitucionais (Smosinki; Harnik, 2013).

Antes de analisarmos o posicionamento adotado pelo STF quanto a essa questão, é necessário destacar que a Constituição Federal de 1988, consolidando

5 São eles: Espírito Santo, Mato Grosso, Acre, Ceará, Mato Grosso do Sul, Santa Catarina e Paraíba. 
os princípios adstritos à noção de Estado democrático de direito, estabeleceu no artigo 37, inciso $\mathrm{V}$, que a investidura em cargos e empregos públicos - tanto na administração direta quanto indireta - dependerá da aprovação prévia em concurso público. Paralelamente à regra geral que institui a obrigatoriedade da realização de concurso, a Carta Constitucional estabelece duas exceções à sua aplicação:

a) no caso de cargos em comissão, de livre nomeação e exoneração, para o exercício temporário de atribuições de direção, chefia ou assessoramento e tendo como base a relação de confiança entre a administração e o servidor comissionado (Moraes, 2007) e

b) na contratação por tempo determinado para atender à necessidade temporária e de excepcional interesse público nas hipóteses previstas em lei, como estabelecido no inciso IX do artigo 37 da Carta Constitucional (Brasil, 1988).

Para a aplicação dessa segunda exceção, são necessários quatro requisitos:

a) existência de lei emanada pela entidade federativa contratante;

b) excepcional interesse público, ou seja, a contratação temporária sem concurso público só é cabível em situações emergenciais, em que o interesse da coletividade permita o afastamento transitório da regra do artigo 37, inciso V, da Constituição Federal;

c) temporariedade da contratação, ou seja, os contratos celebrados entre a administração pública e o os servidores deverão ter prazo determinado;

d) temporariedade da função, ou seja, a necessidade dos serviços contratados sem concurso público deve ser sempre temporária, objetivando a superação de necessidade transitória.

Apesar de existir entre os autores e pesquisadores da área jurídica um esforço em estabelecer critérios e parâmetros para a definição do sentido da expressão "necessidade temporária de excepcional interesse público" contida na Carta Constitucional, trata-se de um conceito aberto e indeterminado e, portanto, passível de múltiplas interpretações. Também em razão da falta de critérios objetivos para esclarecer o sentido da norma contida no artigo 37, inciso IX da Constituição Federal, o STF tem sido constantemente demandado para analisar a constitucionalidade de leis e atos administrativos que preveem a contratação temporária de servidores públicos, inclusive na área educacional.

O posicionamento da corte quanto à temática é o de que, sendo a educação função permanente do Estado, a regra da necessidade de realização de concurso público para contratação de profissionais da educação pública somente poderá ser excepcionada com a comprovação fática e objetiva por parte da administração pública do caráter emergencial da contratação temporária nos termos do artigo 37 , inciso IX da Constituição Federal. A corte destaca ainda que a existência de diversas leis que se sucedem e que preveem a contratação temporária para os mesmos serviços como a contratação de professores - evidenciam ofensa à exceção prevista no artigo citado, sendo, portanto, inconstitucionais. 
É relevante anotar, no entanto, que o STF garantiu à expressão "necessidade temporária de excepcional interesse público" um sentido amplo, afirmando que é admissível a contratação temporária sem a realização de concurso público para o exercício de atividades essenciais - como a educação - desde que haja comprovação de necessidade excepcional temporária, como em caso de carência de profissionais aprovados em concurso público. Ao adotar esse posicionamento jurisprudencial, corre-se o risco de juridicamente abrir excessiva discricionariedade ao Poder Público em relação à contratação temporária de profissionais da educação pública.

Outra importante questão analisada pelo STF diz respeito à constitucionalidade da realização de eleições diretas para a escolha da direção das instituições de ensino mantidas pelo Poder Público - com a participação da comunidade escolar -, prevista no artigo 308, inciso XII, da Constituição Estadual do Rio de Janeiro. Nesse caso, o STF concluiu, com um voto contrário, pela inconstitucionalidade da norma constitucional carioca bem como das demais leis municipais e estaduais que nela se fundamentaram. Tendo como base decisões análogas proferidas anteriormente sobre o tema, o STF entendeu que os dirigentes escolares de estabelecimentos públicos de ensino, por estarem integrados ao organismo do Poder Executivo e por necessariamente desenvolverem com ele relação baseada na confiança, são titulares de cargos em comissão e, por isso, de livre nomeação pelo chefe do Poder Executivo, como previsto no artigo 37, inciso II, da Constituição Federal.

O ministro Marco Aurélio, no entanto, que votou pela constitucionalidade da forma eletiva de escolha dos diretores das escolas públicas, entende que essa está em harmonia com o princípio da gestão democrática de ensino, previsto constitucionalmente no artigo 206, inciso VI. Afirma o ministro que a referida modalidade de investidura de cargo está em sintonia com os anseios da sociedade ao permitir o arrefecimento da atuação discricionária do chefe do Poder Executivo, privilegiando, entre outros aspectos, o mérito dos candidatos, a experiência profissional, a titulação, a aptidão para liderança e a capacidade de gerenciamento. Nesse mesmo sentido, afirmou Sepúlveda Pertence no julgamento de medida liminar referente ao acórdão em análise:

Entendo que a regra geral da competência do Chefe do Poder Executivo para prover cargos públicos e, de modo especial, para prover livremente os cargos em comissão, se antepõe, no caso, uma regra especial, a do art. 206, VI da Constituição, a prever a gestão democrática do ensino público, na forma da lei. Creio que esse dispositivo permite ao legislador ordinário experimentar novas formas de participação da comunidade escolar na direção dos estabelecimentos. (Brasil, 2003, p. 792-793)

Atualmente, coexistem nas escolas públicas do país diferentes modalidades de investidura dos cargos de direção escolar, as quais podem ser resumidas em três espécies: indicação, realização de concurso público e a eleição (Paro, 2003).

As indicações do diretor escolar por um agente político, modalidade defendida pela maioria dos membros do STF, remete ao modelo oligárquico predominante no país durante a República Velha. Observa-se que, para os defensores 
dessa modalidade de escolha do dirigente escolar, a gestão da escola deve seguir a lógica da confiança. Com exceção do posicionamento adotado pelos ministros Marco Aurélio e Sepúlveda Pertence, este, de fato, é o entendimento do STF: o cargo de diretor é, por natureza, cargo em comissão, cuja principal característica é a relação de confiança entre o servidor e aquele que representa o Poder Público naquele momento. Nesse sentido, afirma Cezar Peluso que "os cargos de diretor de escola pública, os quais são em comissão e, como tais, de confiança do Chefe daquele Poder [...]” (Brasil, 2009, p. 132).

Prolonga-se um pouco mais essa questão uma vez que a posição do STF é a de que os cargos de direção são por natureza, e não por lei, cargos de confiança. Trata-se de um fundamento que não encontra respaldo legal, já que o artigo 37, inciso II, afirma de forma explícita que "a investidura em cargo ou emprego público depende de aprovação prévia em concurso público [...], ressalvadas as nomeações para cargo em comissão declarado em lei de livre nomeação e exoneração" (Brasil, 1988). Verifica-se pela simples leitura do artigo que a Constituição exige a existência de uma lei que declare que determinado cargo seja de provimento em comissão. Não existe, nesse seguimento, cargo comissionado por natureza; cargo em comissão é aquele estabelecido pela lei. E, no caso em análise, não existe tal legislação. Observa-se, assim, que o parecer do STF não é simplesmente jurídico, pois, uma vez que a análise legal não autoriza a argumentação da corte, trata-se da própria concepção dos ministros em relação à gestão escolar ou mesmo a falta de conhecimento sobre a temática.

Outra importante questão, de extrema atualidade e relevância na área educacional, também foi objeto de análise pelo STF, a relação entre o público e o privado na educação.

Ao discutir sobre o poder de regulação do Estado em relação aos estabelecimentos privados de ensino, ou seja, sobre a possibilidade de intervenção estatal na atividade exercida pela iniciativa privada no âmbito da educação, nota-se que, embora os ministros tenham travado ferrenha discussão quanto à natureza jurídica dos serviços educacionais - se serviço público, privado ou de natureza dupla - e também em relação à natureza jurídica da relação entre os estabelecimentos privados de ensino e seus usuários - se contratual, se relação de consumo ou pautada no direito fundamental à educação -, a posição majoritária da corte é de que a atuação da iniciativa privada na educação básica não está desatrelada da observância das regras estabelecidas pelo Estado. Em outras palavras, a corte entendeu, por maioria, que a iniciativa privada no âmbito do ensino deve suportar a regulação estatal, inclusive a estabelecida pelos estados membros.

De fato, a Constituição Federal autoriza o exercício da atividade educacional pela iniciativa privada, mas a submete ao dirigismo e regulação estatal. $\mathrm{O}$ artigo 205 da Carta Constitucional, ao estabelecer que a educação é primeiramente dever do Estado, impôs um regime jurídico que confere à administração pública a responsabilidade de não apenas garantir o acesso à educação em estabelecimentos de ensino públicos, mas também de fiscalizar e tutelar a prestação dos serviços educacionais no âmbito privado (Tropardi Filho, 2009). Além disso, o artigo 209 da Constituição Federal é expresso em afirmar que é livre a exploração da atividade educacional 
privada desde que respeitada duas condições: o cumprimento das normas gerais de educação nacional e a autorização e avaliação de qualidade pelo Poder Público (Brasil, 1988). Observa-se assim que a liberdade de iniciativa na área educacional não é irrestrita, estando limitada pelo próprio conteúdo do direito fundamental da educação (Ranieri, 2013).

Em outra questão envolvendo a temática, no entanto, o posicionamento do STF foi diferente. Trata-se da ação direta de inconstitucionalidade n. 1.864, proposta com o objetivo de ver declarada a inconstitucionalidade de dispositivos da lei estadual paranaense n. 11.970/1997, que estabeleceu a criação do PARANAEDUCAÇÃO, pessoa jurídica de direito privado instituída com a finalidade de auxiliar na gestão do sistema estadual de educação (Paraná, 1997). Entre as atribuições do instituto está a de gerir os recursos financeiros de qualquer natureza (públicos e privados) destinados ao desenvolvimento da educação; contratar, administrar e dispensar recursos humanos, inclusive para as atividades de ensino e pesquisa, mediante o regime jurídico da Consolidação das Leis do Trabalho (CLT), e estabelecer o processo de compra de materiais e serviços por meio de procedimentos licitatórios simplificados.

Nesse caso, constata-se no STF a consolidação de duas correntes. A primeira, vitoriosa e formada pela maioria dos ministros, compreende que a educação configura-se como serviço social não exclusivo do Estado, cabendo também à sociedade a sua promoção e que, por tal razão, é legítima a formação de parcerias entre o Poder Público e o terceiro setor (setor privado não lucrativo) na execução e gestão de serviços educacionais. Ademais - e esse é o ponto nevrálgico do acórdão -, a referida corrente adota o entendimento de que o Estado contemporâneo, bem como o direito público atual, deve ajustar-se às novas realidades advindas do mundo globalizado e da competitividade, passando a valorizar a cooperação com a iniciativa privada em áreas tradicionalmente típicas da iniciativa estatal, com foco na melhor eficiência dos serviços sociais. O ministro relator originário da ação, Maurício Corrêa, resume tal posicionamento:

Nessa visão moderna e dinâmica é que o requerido promoveu parceria com pessoa jurídica de direito privado por ele mesmo instituída, como forma de administrar a transição da atuação predominante do Estado no campo da educação pública para inseri-la no mundo da realidade das transformações advindas, quer queira, quer não, com o pragmatismo da globalização e competitividade, de que se assenhorou a hodierna atividade humana [...]. (Brasil, 2007, p. 104)

Uma segunda visão, encabeçada pelos ministros Marco Aurélio e Carlos Britto, compreende a educação como serviço público essencial cuja responsabilidade é essencialmente do Estado, salvo as exceções expressamente previstas no artigo 213 da Constituição Federal. Para esses ministros, em razão da importância dada pela Carta Constitucional à educação, a gestão de seus recursos é de responsabilidade exclusiva do Poder Público, não podendo ser transferida ou compartilhada com o setor privado. Destaque-se que para essa corrente o Estado não está em crise, devendo continuar a existir e a atuar em atividades precípuas, como a área social e, especificamente, a área educacional, já que aí a Constituição Federal não abriu 
espaço para a ampla parceria com o setor privado. Sintetizando a interpretação da lei impugnada, o ministro Marco Aurélio afirma que: "Em última análise, pretende-se privatizar o próprio Estado" (idem, p. 177).

Como pôde ser observado nos casos anteriormente relatados, é possível destacar a falta de diálogo do STF com a área de conhecimento educacional. Com exceção da ação direta de inconstitucionalidade n. 4.167 (Brasil, 2011a), que analisou a constitucionalidade da Lei do Piso Salarial Nacional para os professores, o STF não se utilizou de estudos realizados por autores e pesquisadores da área educacional, não solicitou esclarecimento de peritos em temáticas que envolvessem questões que extrapolassem a dimensão jurídica do direito à educação nem abriu o debate para outros atores da sociedade civil que pudessem fundamentar a decisão judicial nos aspectos propriamente educacionais. É de se destacar que, enquanto os Poderes Executivo e Legislativo possuem uma ampla estrutura de apoio com quadro de pessoal dotado de conhecimentos técnicos e específicos para assessorar na formulação e implementação de políticas públicas de determinada área, o mesmo não pode ser afirmado em relação ao Poder Judiciário (Sarmento, 2010).

A questão parece ser ainda mais complicada em relação ao direito à educação, tendo em vista que, como se observou durante a pesquisa nos votos dos ministros do STF, é comum entre os membros do Poder Judiciário a crença de que, diante da sua experiência educacional como alunos e da sua formação em um curso de graduação da área de ciências sociais, eles têm a capacidade técnica para analisar demandas educacionais. Esse posicionamento é exemplificado pela fala do ministro Sepúlveda Pertence, quando afirmou que no julgamento de ação referente à constitucionalidade de exigência legal de formação específica para ministrar a disciplina de educação artística recorreu-se muito à "experiência comum de que, nas séries mais elementares do ensino fundamental, 'o ensino primário brasileiro', na nossa linguagem, era ministrado por um único professor [...]” (Brasil, 2004, p. 40).

Nesse contexto, entende-se que o juiz não pode ter como objetivo exercer o papel de pedagogo ou negligenciar os estudos e autores da área educacional quando estiver diante de uma demanda relacionada ao direito à educação que extrapole a análise de dispositivos legais. É essencial que se busque informações técnicas, científicas e sociais acerca da temática educacional para que se possa realizar um juízo de valor embasado, não sendo as decisões tomadas apenas com base na lei ou em autores da área jurídica. Se em demandas relacionadas à saúde o parecer de pelo menos um especialista da área médica é sempre solicitado, não haveria razão para agir-se diferente em demandas educacionais.

\section{CONSIDERAÇÕES FINAIS}

O STF, como órgão de cúpula do Poder Judiciário e como tribunal constitucional, tem sido instado a decidir sobre importantes e diversas questões relativas ao direito à educação de crianças e adolescentes na última década. Se inicialmente a temática educacional configurou-se como assunto marginal no STF, constata-se que de 1988 até o início de 2013 foram julgados pela suprema corte cerca de 4.410 processos sobre a temática, dos quais 4.222 foram protocolados a partir de 2001 
(Ranieri, 2013). ${ }^{6}$ Além do significativo aumento de demandas judiciais relacionadas ao direito à educação que foram analisadas pelo STF, pode-se observar também uma mudança nas questões específicas analisadas sobre o tema e também no posicionamento adotado pela corte durante os anos. De fato, enquanto no início dos anos de 1990 prevaleciam decisões relativas à regulação estatal na prestação dos serviços educacionais por estabelecimentos privados de ensino, observa-se na última década um crescimento no número de demandas que requerem a efetivação do direito à educação, especialmente no âmbito da educação básica (idem).

Entre os motivos que podem explicar essa nova realidade, destaquem-se: as diversas alterações constitucionais que ampliaram a garantia do direito à educação, em especial no âmbito da educação infantil, com ênfase para as emendas constitucionais n. 14/1996 e 53/2006 (Brasil, 1996b e 2006, respectivamente); a promulgação de importantes legislações na área educacional, com destaque para a LDB (lei n. 9.394/1996) (Brasil, 1996a) e para o Plano Nacional de Educação (lei n. 10.172/2001) (Brasil,2001); as sucessivas crises (de legitimidade, de confiabilidade e de eficiência) que atingem o Legislativo e o Executivo; o novo papel assumido pelo Ministério Público e pela Defensoria Pública e o protagonismo do Judiciário no campo das políticas públicas.

Quanto ao último aspecto, é de se ressaltar que o fenômeno observado no STF referente ao aumento de demandas judiciais educacionais insere-se no contexto mais amplo da judicialização da política, ou seja, do processo de transferência de questões políticas, tradicionalmente decididas no campo parlamentar e executivo, para o Poder Judiciário (Barboza; Kozicki, 2012). Com a promulgação da Constituição Federal de 1988 e a posterior edição de importantes instrumentos normativos educacionais, passou-se a notar a crescente interferência do Poder Judiciário também no campo da política educacional, o que foi denominado como "judicialização da educação" (Cury; Ferreira, 2009).

De fato, com a passagem constitucional do Estado liberal para o Estado social e democrático de direito, passa-se a exigir do Poder Judiciário, especialmente do STF, como guardião da Constituição Federal, um papel mais ativo na concretização dos direitos sociais, entre os quais os direitos educacionais. Como destaca Vicelli (2012, p. 265):

[...] o modelo de Estado providência (Estado Social) constitui força impulsionadora do ativismo judicial, vez que o Poder Judiciário passa a suprimir etapas determinadas pela burocracia estatal para que formule uma prestação jurisdicional líquida e eficaz que entregue o bem jurídico constitucionalmente garantido.

Nesse contexto, o Judiciário torna-se coautor das políticas públicas (Barboza; Kozicki, 2012), e o STF surge como um dos principais atores desse processo que tem na declaração judicial da garantia dos direitos sociais o seu maior instrumento - e muitas vezes o único. Observa-se assim, pela pesquisa realizada, que o desafio atual

6 Tais processos referem-se, em sua quase totalidade, a decisões monocráticas, razão pela qual não foram contabilizados e analisados na presente pesquisa. 
no processo de ampliação da juridificação e judicialização da educação não está mais em declarar judicialmente o direito fundamental social à educação - o que o STF categoricamente estabeleceu -, e sim em integrar o direito e a área educacional, a interpretação jurídica da lei e os conhecimentos específicos da educação, as decisões judiciais individuais e as políticas públicas educacionais, de forma que a garantia de um direito educacional por meio do Poder Judiciário reflita na garantia efetiva de um direito social à educação para todos.

Deve-se assim, sempre que necessário, “aprofundar o diálogo com a sociedade e com as demais instituições, evitando se restringir às partes formalmente legitimadas" (Neto, 2010, p. 531). Se a interferência do Poder Judiciário no campo das políticas públicas educacionais já é realidade, com tendência à expansão, deve-se destacar que a construção de uma decisão judicial que realmente reflita na prática social e que dialogue com o campo educacional é o significado dado pela Constituição Federal ao direito fundamental social à educação.

\section{REFERÊNCIAS}

Barboza, E. M. Q.; Kozicki, K. Judicialização da política e controle judicial de políticas públicas. Revista Direito GV, São Paulo: Fundação Getúlio Vargas, v. 8, n. 1, p. 59-86, jan./jun. 2012.

Brasil. Lei n. 5.869, de 11 de janeiro de 1973. Institui o Código de Processo Civil. Diário Ofcicial da União, Brasília, DF, 17 jan. 1973. Disponível em: <http://www.planalto. gov.br/ccivil_03/leis/15869compilada.htm>. Acesso em: 20 jan. 2013.

. Constituição. Constituição da República Federativa do Brasil de 1988. Brasília, 5 out. 1988. [Versão atualizada até a emenda n. 90, de 15 set. 2015]. Disponível em: <http://www.planalto.gov.br/ccivil_03/Constituicao/Constituicao.htm>. Acesso em: 30 out. 2015.

. Lei n. 9.394, de 20 de dezembro de 1996. Estabelece as diretrizes e bases da educação nacional. Diário Oficial da União, Brasília, DF, 23 dez. 1996a. Disponível em: <http://www.planalto.gov.br/ccivil_03/Leis/L9394.htm>. Acesso em: 8 jan. 2016.

.Emenda Constitucional n. 14, de 12 de setembro de 1996. Modifica os arts. 34, 208, 211 e 212 da Constituição Federal e dá nova redação ao art. 60 do Ato das Disposições constitucionais Transitórias. Diário Oficial da União, Brasília, DF, 13 set. 1996b. Disponível em: <http://www.planalto.gov.br/ccivil_03/constituicao/emendas/emc/emc14. htm>. Acesso em: 8 jan. 2016.

Lei n. 10.172, de 9 de janeiro de 2001. Aprova o Plano Nacional de Educação e dá outras providências. Diário Oficial da União, Brasília, DF, 10 jan. 2001. Disponível em: <http://www.planalto.gov.br/ccivil_03/leis/leis_2001/110172.htm>. Acesso em: 8 jan. 2016.

. Supremo Tribunal Federal. Medida cautelar em ação direta de inconstitucionalidade n. 2.997. Relator Ministro Cezar Peluso. Brasília, DF, 2003.

. Supremo Tribunal Federal. Ação direta de inconstitucionalidade n. 1.399. Relator Ministro Maurício Corrêa. Brasília, DF, 2004. 
Supremo Tribunal Federal. Agravo regimental no recurso extraordinário n. 410.715. Relator Ministro Celso de Mello. Brasília, DF, 2005.

. Emenda Constitucional n. 53, de 19 de dezembro de 2006. Dá nova redação aos arts. 7o ,23, 30, 206, 208, 211 e 212 da Constituição Federal e ao art. 60 do Ato das Disposições constitucionais transitórias. Diário Oficial da União, Brasília, DF, 20 dez. 2006. Disponível em: <http://www.planalto.gov.br/ccivil_03/constituicao/Emendas/ Emc/emc53.htm>. Acesso em: 8 jan. 2016.

. Supremo Tribunal Federal. Ação direta de inconstitucionalidade n. 1.864. Relator Ministro Maurício Corrêa. Brasília, DF, 2007.

. Supremo Tribunal Federal. Ação direta de inconstitucionalidade n. 2.997. Relator Ministro Cezar Peluso. Brasília, DF, 2009.

. Supremo Tribunal Federal. Ação direta de inconstitucionalidade n. 4.167. Relator Ministro Joaquim Barbosa. Brasilia, DF, 2011a.

. Supremo Tribunal Federal. Ação direta de inconstitucionalidade n. 4.277. Relator Ministro Ayres Britto. Brasília, DF, 2011b.

. Supremo Tribunal Federal. Arguição de descumprimento de preceito fundamental n. 132. Relator Ministro Ayres Britto. Brasília, DF, 2011c.

. Supremo Tribunal Federal. Recurso Extraordinário n. 597.285. Relator Ricardo Lewandowski. Brasília, DF, 2012a.

. Supremo Tribunal Federal. Arguição de descumprimento de preceito fundamental n. 54. Relator Ministro Marco Aurélio. Brasília, DF, 2012b.

Caggiano, M. H. S. A educação: direito fundamental. In: Ranieri, N. B. S. (Coord.); Righetti, S. (Org.). Direito à educação: aspectos constitucionais. São Paulo: EDUSP, 2009. p. 19-38.

Cury, C. R. J.; Ferreira, L. A. M. A judicialização da educação. Revista CEJ, Brasília: Centro de Estudos Judiciários, ano XIII, n. 45, p. 32-45, abr./jun. 2009.

Duarte, C. S. Direito público subjetivo e políticas educacionais. São Paulo em Perspectiva, São Paulo: Fundação SEADE, v. 18, n. 2, p. 113-118, jun. 2004.

. A educação como um direito fundamental de natureza social. Educação छ Sociedade, Campinas: CEDES, v. 28, n. 100, p. 691-713, out. 2007.

Ferreira, S.; Fernandes, E. B. D. O STF nas "Cortes" Victor Nunes Leal, Moreira Alves e Gilmar Mendes. Revista Direito GV, São Paulo: Fundação Getúlio Vargas, v. 9, n. 1, p. 23-45, jan./jun. 2013.

Monteiro, A. R. O pão do direito à educação. Educação É Sociedade, Campinas: CEDES, v. 24, n. 84, p. 763-789, set. 2003.

Moraes, A. Direito constitucional. 22. ed. São Paulo: Atlas, 2007.

Nery Junior, N. Código de Processo Civil comentado e legislação extravagante. São Paulo: Revista dos Tribunais, 2006.

Neto, C.P. S. A justiciabilidade dos direitos sociais: críticas e parâmetros. In:

Sarmento, D. (Coords.). Direitos sociais: fundamentos, judicialização e direitos sociais em espécie. 2. ed. Rio de Janeiro: Lumen Juris, 2010. p. 515-551. 
Oliveira, D. A. A reestruturação do trabalho docente: precarização e flexibilização. Educação E Sociedade, Campinas: CEDES, v. 25, n. 89, p.1.127-1.144, set./dez. 2004. Oliveira, R.L.P.; Araujo, G. C. Qualidade do ensino: uma nova dimensão da luta pelo direito à educação. Revista Brasileira de Educação, Rio de Janeiro: ANPEd; Campinas: Autores Associados, n. 28, p. 5-23, jan./abr. 2005.

PARANá. Lei n. 11.970, de 19 de dezembro de 1997. Institui o PARANAEDUCAÇÃO, pessoa jurídica de direito privado, sob a modalidade de serviço social autônomo, na forma que especifica. Diário Oficial do Estado do Paraná, Curitiba, PR, 19 dez. 1997. Disponível em: <http://www.legislacao.pr.gov.br/legislacao/pesquisarAto. do? action $=$ exibir\&codAto $=8825 \& \operatorname{codTipoAto}=\&$ tipoVisualizacao $=$ original $>$. Acesso em: 8 jan. 2016.

Paro, V. H. Eleição de diretores: a escola pública experimenta a democracia. São Paulo: Xamã, 2003.

Pinto, I. R. R. A garantia do direito à educação de crianças e adolescentes pela via judicial: análise das decisões judiciais do Supremo Tribunal Federal (2003-2012). 2014. 215p. Dissertação (Mestrado) - Faculdade de Educação, Universidade Federal da Grande Dourados, Dourados, 2014.

Ranieri, N. B. S. O direito educacional no sistema jurídico brasileiro. In: KIM, R. P.; Ferreira, L. A. M. (Orgs.).Justiça pela qualidade na educação. São Paulo: Saraiva, 2013. p. 55-103.

Rebell, M. A. Educational adequacy, democracy and the Courts. Washington, DC: The National Academies Press, 2002.

Ribeiro, R. S. Política e economia na jurisdição constitucional abstrata (1999-2004). Revista Direito GV, São Paulo: Fundação Getúlio Vargas, v. 8, n. 1, p. 87-108, jan./ jun. 2012.

Sarmento, D. A proteção judicial dos direitos sociais: alguns parâmetros ético-jurídicos. In: Neto, C.P. S.; Sarmento, D. (Coords.). Direitos sociais: fundamentos, judicialização e direitos sociais em espécie. 2. ed. Rio de Janeiro: Lumen Juris, 2010. p. 553-586.

Silva, J. A. Curso de direito constitucional positivo. 28. ed. São Paulo: Malheiros, 2007.

Silveira, A. A. D. O direito à educação de crianças e adolescentes: análise da atuação do Tribunal de Justiça de São Paulo (1991-2008). 2010. 303f. Tese (Doutorado em Educação) - Faculdade de Educação, Universidade de São Paulo, São Paulo, 2010.

. Atuação do Tribunal de Justiça de São Paulo com relação ao direito de crianças e adolescentes à educação. Revista Brasileira de Educação, Rio de Janeiro: ANPEd; Campinas: Autores Associados, v. 17, n. 50, p. 353-368, maio/ago. 2012.

Smosinki, S.; Harnik, S. Em 7 Estados, mais da metade dos contratos de professores são temporários. UOL, São Paulo, 8 maio 2013. UOL Educação, 2013. Disponível em: $<$ http://educacao.uol.com.br/noticias/2013/05/08/em-7-estados-mais-da-metade-doscontratos-de-professores-sao-temporarios.htm>. Acesso em: 18 nov. 2013.

Tavares, A. R. Direito fundamental à educação. In: Neto, C. P. S.; Sarmento, D. (Coords.). Direitos sociais: fundamentos, judicialização e direitos sociais em espécie. 2. ed. Rio de Janeiro: Lumen Juris, 2010. p. 771-789. 
Tropardi Filho, L. A exploração da atividade educacional pela iniciativa privada e seus limites legais. In: Ranieri, N. B. S. (Coord.); Righetti, S. (Org.). Direito à educaşão: aspectos constitucionais. São Paulo: EDUSP, 2009. p. 219-240.

Verbicaro, L. P. Um estudo sobre as condições facilitadoras da judicialização da política no Brasil. Revista Direito GV, São Paulo: Fundação Getúlio Vargas, v. 4, n. 2, p. 389-406, jul./dez. 2008.

Vicelli, R. D. C. O ciclo de judicialização das políticas públicas: a Lei de Diretrizes e Bases da Educação Nacional de 1996 e os efeitos indiretos externos das decisões do STJ e STF. Revista de Direito Educacional, São Paulo: Revista dos Tribunais, ano 3, v. 6, p. 261-283, jul./dez. 2012.

Vieira, O.V. Supremocracia. Revista Direito GV, São Paulo: Fundação Getúlio Vargas, v. 4, n. 2, p. 441-463, jul./dez. 2008.

\section{SOBRE AS AUTORAS}

Elisângela Alves da Silva Scaff é doutora em educação pela Universidade de São Paulo (USP). Professora da Universidade Federal da Grande Dourados (UFGD).

E-mail: elisangelascaff@ufgd.edu.br

Isabela Rahal de Rezende Pinto é doutoranda pela Universidade de São Paulo (USP).

E-mail: isabelarahal@hotmail.com

Recebido em maio de 2014

Aprovado em março de 2015 